\title{
Spontaneous and in vitro fertilization pregnancies have comparable first trimester screening profiles for Down syndrome
}

\author{
(D) Yılmaz Güzel ${ }^{1}$, (D) Engin Türkgeldi², (D) Hande Yağmur², (D) Zeki Salar1, (D) Başak Balaban¹, (D Bülent Urman¹,2, \\ (D) Özgür Öktem 1,2 \\ 1Assisted Reproduction Unit, American Hospital, Women's Health Center, İstanbul, Turkey \\ 2Department of Obstetrics and Gynecology, Koç University Faculty of Medicine, İstanbul, Turkey
}

\section{Abstract}

Objective: We aimed to compare the first trimester screening profiles of spontaneous $(n=972)$ and in in vitro fertilization (IVF) pregnancies $(\mathrm{n}=339)$ in a population of patients who had uncomplicated singleton pregnancies comparable for maternal age, gestation, body mass index, and ethnicity.

Material and Methods: A non-interventional analysis of retrospective cohort data and review of the literature.

Results: All IVF pregnancies were achieved via intracytoplasmic sperm injection using the same ovarian stimulation protocol with recombinant follicle-stimulating hormone and a gonadotropin-releasing hormone antagonist, cetrorelix acetate. The means of the multiple of median (MoM) of pregnancy-associated plasma protein-A (PAPP-A) were slightly lower in the fresh $(1.19 \pm 0.6$ vs $1.33 \pm 0.7$, respectively; $\mathrm{p}=0.056)$ and frozen embryo transfer ( $1.03 \pm 0.5$ vs $1.33 \pm 0.7$, respectively; $p=0.036)$ IVF pregnancies compared with natural conceptions. However, when the medians of the MoMs of PAPP-A and beta-human chorionic gonadotrophin ( $\beta-\mathrm{hCG})$, and their distributions were compared across the mode of conception, there were no differences between IVF pregnancies spontaneous pregnancies. Furthermore, the scatterplot diagram and curve fitting regression analyses revealed no difference in the temporal relations of $\beta$-hCG and PAPP-A with each other and gestational age between spontaneous and IVF pregnancies.

Conclusion: These results support the notion that uncomplicated singleton IVF pregnancies have similar first trimester screening profiles to spontaneous conceptions. (J Turk Ger Gynecol Assoc 2019; 20: 97-105)

Keywords: First trimester screening, pregnancy-associated plasma protein-A, beta-human chorionic gonadotrophin, nuchal translucency, pregnancy, in vitro fertilization, intracytoplasmic sperm injection

Received: 9 May, 2018 Accepted: 10 September, 2018

\section{Introduction}

Prenatal screening for chromosomal abnormalities using maternal serum and sonographic markers has been integrated into routine antenatal care in many countries. First trimester screening test combines maternal age, nuchal translucency (NT), maternal serum pregnancy-associated plasma protein-A (PAPP-A), and free beta-human chorionic gonadotrophin $(\beta-\mathrm{hCG})$ to generate a risk assessment for Down syndrome and other trisomies. This method has been reported to identify about
$90 \%$ of cases of trisomy 21 with a $5 \%$ false-positive rate $(1,2)$. An increasing number of pregnancies are achieved through assisted reproductive technologies (ART) every year. Several studies demonstrated that pregnancies conceived through ART are associated with altered maternal levels of the biomarkers of the first trimester screening, affecting the risk assessment for Down syndrome (3-10). A decrease in the maternal serum level of PAPP-A and normal or higher levels of $\beta$-hCG in in vitro fertilization (IVF) pregnancies appear to be the most consistent findings of these studies including the result of a recent meta- 
analysis $(3-5,7,11,12)$. On the other hand, some other reports found no differences in the levels of these biomarkers between natural and IVF pregnancies (13-16).

Apparently, the inconsistent results among the studies are likely to be accounted for by several confounding factors such as heterogeneous patient populations, maternal age, and adverse obstetric outcomes. Notably, the levels of these biomarkers remained to be altered in some of these studies after adjusting for these variables and excluding cases with poor obstetric events $(5,6)$. There are also limited data regarding the comparison of IVF pregnancies after fresh vs. frozen embryo transfer (ET) cycles in terms of their effect on the parameters of the first trimester test. Therefore, we conducted this retrospective cohort study in a homogeneous population of patients who were comparable for maternal age, gestation, body mass index (BMI) and ethnicity and had uncomplicated singleton pregnancies ending in the birth of full-term neonates. Our aims were to investigate whether (1) IVF pregnancies achieved after fresh and frozen ET IVF cycles were different from natural conceptions in terms of the first trimester test results in a patient cohort comprising uncomplicated singleton pregnancies; and (2) there were any differences in these parameters between fresh and frozen ET IVF pregnancies conceived using the same ovarian stimulation protocol with recombinant follicle-stimulating hormone (FSH) and a gonadotropin-releasing hormone $(\mathrm{GnRH})$ antagonist.

\section{Material and Methods}

\section{Patients}

In this retrospective cohort study, the first trimester screening profiles of spontaneous $(n=972)$ and IVF pregnancies $(n=339)$ in a population of patients who had uncomplicated singleton pregnancies comparable for maternal age, gestation, BMI, and ethnicity were analyzed. All singleton pregnancies whose first trimester screening results were available were included. Of these, only 24 were excluded because of no information on pregnancy outcome $(n=10)$, preeclampsia $(n=4)$, gestational diabetes $(n=2)$, which left 1331 for further evaluation. All pregnancies were singleton, uncomplicated and resulted in full term birth (37 completed weeks of gestation) of healthy neonates in a private hospital between January 2009 and July 2014. Nine hundred seventy-two of these were spontaneous pregnancies, whereas the remaining 339 were achieved through IVF-ICSI after the transfer of fresh $(n=301)$ and frozen $(n=38)$ embryos. The study was approved by the institutional review board of Koç University (IRB\# 2015.207.IRB2.077, date: 10.09.2015). The study was performed in accordance with the ethical standards described in Declaration of Helsinki. For each patient, age at the time of the test, ethnicity, weight, smoking status, diabetes history, any previous pregnancy with trisomy, family history of trisomy, date of last menstrual period, crownrump length (CRL), nuchal translucency, and serum PAPP-A and $\beta$-hCG levels and their multiple of median (MoM) values were recorded. All patients had Turkish ethnic background. A systematic literature search was performed using the key words provided to retrieve the relevant articles.

\section{Fertility treatment}

Fertility treatment records were reviewed to identify IVFICSI pregnancies after fresh and frozen ET. All embryos were generated via IVF-ICSI using ovarian stimulation with recombinant FSH (Gonal-F) and a GnRH antagonist, cetrorelix acetate. In fresh transfer cycles, 8\% progesterone gel was started vaginally once a day on the day of the oocyte pick-up, and the frequency was increased to twice a day on the transfer day. No estrogen support was administered for fresh transfers. For frozen-thawed ET, endometrial preparation was provided with oral estrogen and vaginal progesterone gel. Patients were given a tablet of $2 \mathrm{mg}$ estradiol/day in the first 4 days of the cycle, 2 tablets/day on the next 4 days, and 3 tablets/day thereafter. Eight percent progesterone gel was administered once daily 3-5 days before the transfer and twice a day starting on the day of the transfer. All medications were used until the $8^{\text {th }}$ gestational week if pregnancy was achieved.

\section{Risk assessment using the first trimester combined test}

All patients underwent the first trimester screening test between $11+0$ and $13+6$ weeks of gestation. Gestational age was determined using CRL. NT was measured according to the Fetal Medicine Foundation protocol by the same physicians (17). For all cases, blood samples was obtained on the day of the NT scan for measurement of maternal PAPP-A and $\beta$-hCG levels and analyzed using a Delfia ${ }^{\odot}$ Express 6000 Immunoanalyzer (PerkinElmer, Waltham, Massachusetts, USA). Down syndrome risk was calculated using the LifeCycle 2.2 Rev. 4 software (PerkinElmer, Waltham, Massachusetts, USA).

\section{Statistical analysis}

Demographic characteristics of the patients (maternal age, body weight, gestational age, BMI, and CRL) are expressed as mean \pm standard deviation (SD) (Table 1). The MoM of the markers of the first trimester screening (NT, $\beta$-hCG and PAPP-A) are expressed as mean, median, $\mathrm{SD}$, and percentile $(25,50,75)$ (Table 2). The variables in the baseline demographic characteristics and the means of the MoMs between spontaneous and IVF (overall) pregnancies were compared using the t-test and MannWhitney U test, respectively. Additionally, spontaneous and IVF pregnancies conceived after fresh and frozen ET cycles were compared using the Kruskal-Wallis test and Dunn's multiple 
comparison posthoc test. The variables were also tested as to whether they were distributed normally using the Kolmogorov Smirnov one-sample test. The medians of the MoMs and their distributions were compared using Wilcoxon's signed-rank test to explore if the mode of conception had any influence on these parameters. The two-tailed pearson correlation test and linear regression analysis were conducted to investigate the relationship among the variables in the first trimester screening test. $\mathrm{P}<0.05$ was considered significant. Data analysis was performed using SPSS (version 21; SPSS Inc., Chicago, IL, USA).

\section{Results}

Baseline characteristics of the study population are shown in the Table 1. Control and IVF-ICSI patients were comparable in terms of mean age ( $31.5 \pm 3.7$ vs $32.2 \pm 4.7$ years, respectively; $p>0.05$ ), weight ( $64.5 \pm 10.1$ vs $63.6 \pm 9.6 \mathrm{~kg}$, respectively; $\mathrm{p}>0.05)$, BMI ( $20.8 \pm 2.5$ vs $21.2 \pm 3.4 \mathrm{~kg} / \mathrm{m}^{2}$, respectively; $\mathrm{p}>0.05$ ), gestational age (89.1 \pm 4.7 vs $89.1 \pm 5.6$ days, respectively; $p>0.05$ ), and CRL (64.1 \pm 5.7 vs $64.2 \pm 6.1 \mathrm{~mm}$, respectively; $\mathrm{p}>0.05$ ).

Comparison of the mean MoM levels of the test biomarkers between spontaneous and IVF-ICSI pregnancies

Fetal NT and maternal blood levels of $\beta$-hCG and PAPP-A are expressed as MoMs. The mean \pm SD, median, and percentiles $(25,50,75)$ of the MoMs are shown in Table 2. First, we compared the means of the MoMs between spontaneous and IVF-ICSI (overall) pregnancies as two independent samples from a continuous field. There were no significant differences between these two different modes of conception in the mean MoM levels of $\beta$-hCG $(1.24 \pm 0.8$ vs $1.29 \pm 0.9$, respectively; $\mathrm{p}>0.05)$, PAPP-A ( $1.33 \pm 0.9$ vs $1.18 \pm 0.8$, respectively; $\mathrm{p}>0.05$ ), and NT (1.06 \pm 0.4 vs $1.11 \pm 0.4$, respectively; $p>0.05)$ (Table 1 ). Then, IVF pregnancies were subgrouped into fresh and frozen ET cycle IVF pregnancies and a multiple comparison was made among spontaneous, fresh, and frozen IVF pregnancies. The means of the MoM of PAPP-A were significantly lower in the fresh $(1.19 \pm 0.6$ vs $1.33 \pm 0.7$, respectively; $\mathrm{p}=0.056)$ and frozen ET
$(1.03 \pm 0.5$ vs $1.33 \pm 0.7$, respectively; $p=0.036)$ IVF pregnancies compared with spontaneous pregnancies. The MoMs of $\beta$-hCG ( $1.24 \pm 0.6$ vs $1.26 \pm 0.8$ vs $1.48 \pm 0.8$, respectively; $p>0.05)$ and NT ( $1.06 \pm 0.8$ vs $1.13 \pm 0.8$ vs $1.01 \pm 0.8$, respectively; $p>0.05)$ showed significant variations among spontaneous, fresh, and frozen ET IVF pregnancies. Furthermore, IVF pregnancies occurring after fresh ET cycles were not different from those after frozen ET cycles in terms of the mean MoM levels of these biomarkers (Table 2).

Comparison of the medians of the MoMs across the mode of conception and their distribution between spontaneous and IVF pregnancies

When the medians of the MoMs of $\beta$-hCG, PAPP-A and NT of IVF pregnancies were compared with the corresponding medians in the spontaneous pregnancies, no significant differences were found between spontaneous and IVF pregnancies regarding the distribution and median MoMs of the biomarkers (Table 2). The asymptotic significances were as follows: 0.544 for $\beta$-hCG, 0.89 for PAPP-A, and 0.53 for NT (Table 2). The MoMs of $\beta$-hCG, PAPP-A, and NT were not normally distributed in either spontaneous or IVF pregnancies on the KolmogorovSmirnov test.

Comparison of spontaneous and IVF pregnancies for the temporal relationship among $\beta$-hCG, PAPP-A, and gestational age

Both $\beta$-hCG and PAPP-A are produced by trophoblastic tissue during pregnancy (1). Thus, we investigated the temporal relationship between these biomarkers in spontaneous and IVF pregnancies using correlation analyses. Two-tailed pearson correlation analysis revealed that $\beta$-hCG was positively correlated with PAPP-A in both spontaneous (correlation coefficient: $0.22, \mathrm{p}<0.001$ ) and IVF pregnancies (correlation co-efficient: $0.21, \mathrm{p}<0.001$ ). There was also a positive correlation between gestational age and $\beta$-hCG in spontaneous (correlation co-efficient: 0.12, $\mathrm{p}<0.001$ ) and IVF pregnancies

Table 1. Comparison of the demographic characteristics of the spontaneous and IVF pregnancies

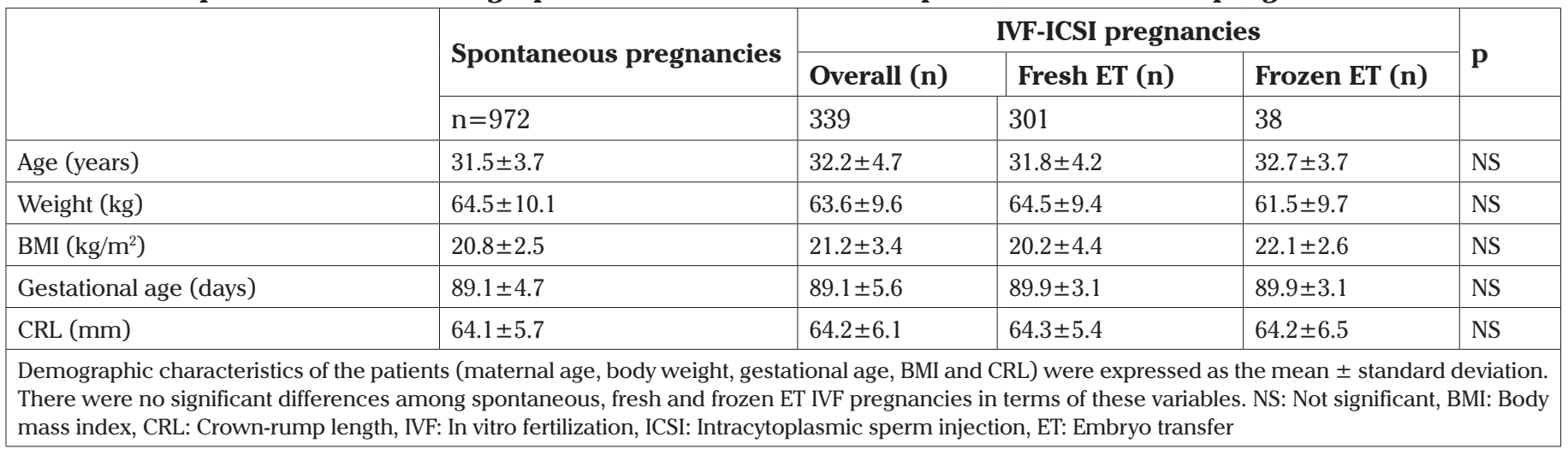


(correlation co-efficient: $0.14, \mathrm{p}=0.014$ ). Gestational age was inversely correlated with PAPP-A in spontaneous (correlation co-efficient: $-0.13, \mathrm{p}<0.001$ ) and IVF pregnancies (correlation co-efficient: $-0.11, \mathrm{p}=0.013$ ). In the linear regression analysis, $\beta$-hCG $\left(R^{2}=0.10, p=0.002\right)$ and PAPP-A $\left(R^{2}=-0.15, p<0.001\right)$ remained significantly associated with gestational age in spontaneous conceptions. Similar associations were found between $\beta$-hCG and gestational age $\left(R^{2}=0.14, p=0.017\right)$, and between PAPP-A and gestational age $\left(\mathrm{R}^{2}=-0.12, \mathrm{p}=0.013\right)$ in IVF pregnancies (Figure 1).

\section{Discussion}

We used different statistical models in this study to analyze and compare the first trimester screening test results of spontaneous and IVF pregnancies. Similar to some previous reports, we showed that IVF pregnancies had slightly lower
$1 \mathrm{~A}$
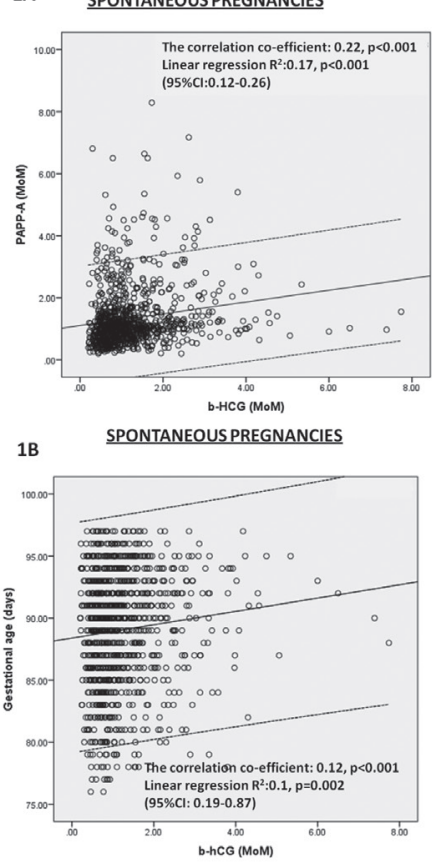

1C SPONTANEOUS PREGNANCIES

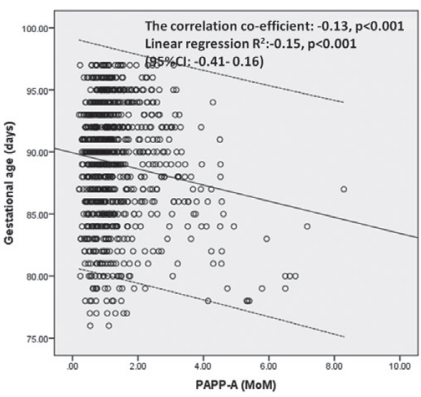

IVF PREGNANCIES

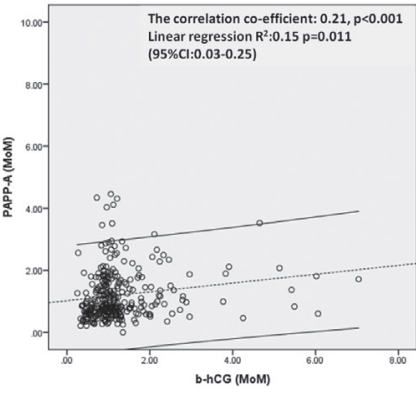

IVF PREGNANCIES

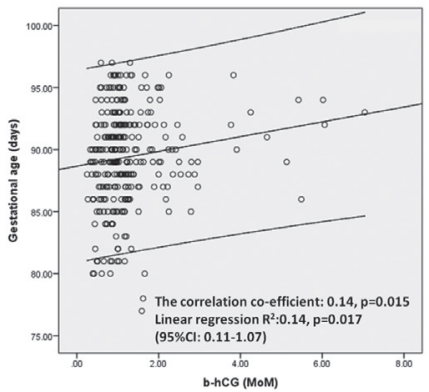

IVF PREGNANCIES

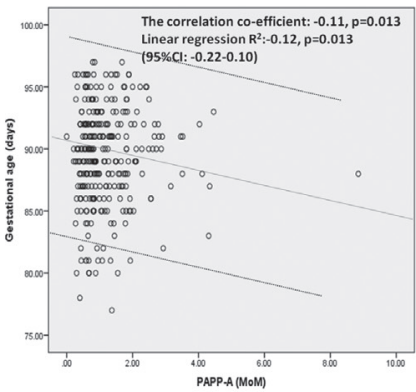

Figure 1. Temporal relationship between gestational age, $\beta$-hCG and PAPP-A in spontaneous and IVF pregnancies -hCG: $\beta$-human chorionic gonadotropin, PAPP-A: Pregnancy associated plasma protein-A, IVF: In vitro fertilization
PAPP-A, and similar $\beta$-hCG and NT levels compared with spontaneously conceived pregnancies when both groups consist of uncomplicated singleton pregnancies comparable for maternal age, gestation, weight, BMI, and ethnicity. Also, we find no differences in these parameters between the pregnancies after fresh and frozen ET cycles.

A number of studies examined the possible effects of IVF on first trimester screening test results. These studies are summarized in Table 3. The majority of them reported decreased MoM levels of PAPP-A for both IVF and ICSI pregnancies (3-10) as the most consistent finding (Table 3). As a result of lower PAPP-A levels, higher false-positive rates were reported in the combined screening test of IVF pregnancies (18). PAPP-A is a placental derived protein and its synthesis is defective in Down syndrome due to the impaired differentiation of cyto to syncytiotrophoblasts in the placenta (19). Therefore, maternal PAPP-A levels are lower in fetuses with trisomy 21. However, given that the incidence of births of the fetuses with trisomy 21 was not increased in IVF pregnancies, there must be some other mechanisms that could provide a plausible explanation for the observed decrease in the PAPP-A level and higher false-positive rates of the first trimester screening in these pregnancies. To date, several hypotheses have been put forth to explain this phenomenon. Tul and Novak-Antolic (10) demonstrated that there was an inverse association between the number of aspirated oocytes and PAPP-A MoM values and that inhibin $\mathrm{A}$, a product of the corpus luteum, was increased with decreasing PAPP-A and increasing the number of oocytes retrieved. Based on these findings, the investigators hypothesized that ovarian stimulation was associated with the generation of multiple corpora lutea and higher endogenous levels of inhibin A, which in turns inhibits the secretion of PAPP-A. Currently this hypothesis lacks biologic validation and cannot explain the others' findings showing normal levels of PAPP-A in IVF pregnancies in comparison to controls (13-16). Furthermore, lower maternal PAPP-A levels were also reported in IVF pregnancies after frozen ET cycles, in which the ovaries are not stimulated, and therefore there are no multiple corpora lutea or elevated serum levels of inhibin-A $(3,20)$.

Decreased PAPP-A levels are not specific for Down syndrome because it is also measured at lower levels in euploid pregnancies complicated by defective placentation such as pre-eclampsia and fetal growth restriction (21). This fact raises a question as to whether lower PAPP-A levels may indicate impairment of early implantations of the pregnancies in IVF populations. Currently, there is no good evidence to prove this claim, but it is known that IVF/ICSI pregnancies are more prone to developing adverse obstetric outcomes than natural conceptions. Thus, could lower PAPP-A levels in these pregnancies be the harbinger of poor obstetric events in the 
future? The answer is probably no because maternal PAPP-A level continues to remain low even in uncomplicated IVF pregnancies when all cases with obstetric complications were excluded $(5,6)$. Furthermore a recent study comparing first trimester trophoblast volume and placental bed vascular volume between IVF/ICSI $(n=70)$ and normal singleton pregnancies $(n=84)$ using a virtual organ computer-aided analysis system demonstrated no differences in these parameters between spontaneous and IVF pregnancies (22).

Interestingly, it was shown that subfertility itself and the etiology of infertility may also alter the levels of maternal PAPP-A. For instance, time to pregnancy (TTP) is a clinical tool to assess uterine receptivity/subfertility. Ranta et al. (23) demonstrated that the median/geometric mean multiple of MoM of PAPP-A was significantly lower $(\mathrm{p}<0.01)$ in women with a TTP over 25 months (0.89/0.83 MoM) and in the IVF group (0.95/0.84 MoM) compared with the reference group (1.01/1.03 MoM). However, first trimester $\beta$-hCG and NT MoMs were not statistically different between the study groups. Consequently, the proportion of the test screening positives was significantly higher in women with TTP $\geq 25$ months (12.9 vs $2.1 \%$ ), but not in the IVF group (2.6\%). Regarding the effect of infertility on the test results, a recordlinkage study showed that PAPP-A levels were reduced when the infertility was reported to be of female-only etiology ( 0.82 MoM), male-only etiology ( $0.85 \mathrm{MoM})$, and when a combination of male and female etiologies were present in the couple $(0.82$ MoM) (3).

Advanced maternal age among patients who become pregnant after IVF/ICSI appears to be another factor responsible, at least in part, for the higher false-positive rate of the test in these

Table 2. Comparison of the first trimester biomarkers among spontaneous, fresh and frozen cycle IVF pregnancies

\begin{tabular}{|c|c|c|c|c|c|}
\hline & \multirow{2}{*}{$\begin{array}{l}\text { Spontaneous } \\
\text { pregnancies }\end{array}$} & \multicolumn{3}{|c|}{ IVF-ICSI pregnancies } & \multirow{2}{*}{ p value } \\
\hline & & Overall & Fresh ET & Frozen ET & \\
\hline $\begin{array}{l}\text { Free } \beta \text {-hCG (MoM) } \\
\text { Mean } \\
\text { Median } \\
\text { Standard deviation } \\
\text { Percentiles } \\
25 \\
50 \\
75\end{array}$ & $\begin{array}{l}1.24 \\
1.00 \\
0.87 \\
\\
0.67 \\
1.00 \\
1.53\end{array}$ & $\begin{array}{l}1.29 \\
1.03 \\
0.93 \\
\\
0.82 \\
1.03 \\
1.35\end{array}$ & $\begin{array}{l}1.26 \\
1.04 \\
0.93 \\
\\
0.82 \\
1.04 \\
1.33\end{array}$ & $\begin{array}{l}1.48 \\
1.00 \\
0.62 \\
\\
0.80 \\
1.00 \\
1.71\end{array}$ & $\mathrm{a}, \mathrm{b}, \mathrm{c}$ \\
\hline $\begin{array}{l}\text { PAPP-A (MoM) } \\
\text { Mean } \\
\text { Median } \\
\text { Standard deviation } \\
\text { Percentiles } \\
25 \\
50 \\
75\end{array}$ & $\begin{array}{l}1.33 \\
1.06 \\
0.98 \\
\\
0.76 \\
1.06 \\
1.51 \\
\end{array}$ & $\begin{array}{l}1.18 \\
0.88 \\
0.88 \\
\\
0.60 \\
0.88 \\
1.50 \\
\end{array}$ & $\begin{array}{l}1.19 \\
0.89 \\
0.90 \\
\\
0.61 \\
0.89 \\
1.55\end{array}$ & $\begin{array}{l}1.03 \\
0.80 \\
0.69 \\
\\
0.55 \\
0.80 \\
1.38 \\
\end{array}$ & $\mathrm{a}, \mathrm{b}, \mathrm{c}$ \\
\hline $\begin{array}{l}\text { NT (MoM) } \\
\text { Mean } \\
\text { Median } \\
\text { Standard deviation } \\
\text { Percentiles } \\
25 \\
50 \\
75\end{array}$ & $\begin{array}{l}1.06 \\
1.02 \\
0.46 \\
\\
0.86 \\
1.02 \\
1.17\end{array}$ & $\begin{array}{l}1.11 \\
1.00 \\
0.57 \\
\\
0.84 \\
1.00 \\
1.19 \\
\end{array}$ & $\begin{array}{l}1.13 \\
0.99 \\
0.59 \\
\\
0.80 \\
0.98 \\
1.20 \\
\end{array}$ & $\begin{array}{l}1.01 \\
1.06 \\
0.21 \\
\\
0.85 \\
1.06 \\
1.16\end{array}$ & $\mathrm{a}, \mathrm{b}, \mathrm{c}$ \\
\hline \multicolumn{6}{|c|}{$\begin{array}{l}\text { The MoM of the markers of the first trimester screening (NT, free } \beta \text {-hCG and PAPP-A) were expressed as the mean, median, standard deviation, and the } \\
\text { percentile }(25,50,75) \text {. The means of the MoM of PAPP-A were slightly lower in the fresh IVF pregnancies compared to natural conceptions. However, when } \\
\text { the medians of the MoMs of PAPP-A and free } \beta \text {-hCG, and their distributions were compared across the mode of conception, IVF pregnancies were not any } \\
\text { different from spontaneous ones. } \\
\text { a: } p>0.05 \text { when the means were compared between spontaneous vs IVF pregnancies (overall) using the Mann-Whitney U test. } \\
\mathrm{b}: \mathrm{p}<0.05 \text { when multiple groups were compared with Kruskal-Wallis and multiple comparison posthoc test. Spontaneous vs fresh IVF: } \mathrm{p}=0.25 \text { for } \beta \text {-hCG; } \\
\mathrm{p}=0.056 \text { for PAPP-A; } \mathrm{p}=0.83 \text { for NT. Spontaneous vs frozen IVF: } \mathrm{p}=0.91 \text { for } \beta \text {-hCG; } \mathrm{p}=0.036 \text { for PAPP-A; } \mathrm{p}=0.73 \text { for NT. Fresh vs frozen IVF: } \mathrm{p}=0.27 \text { for } \beta \text {-hCG; } \\
\mathrm{p}=0.31 \text { for PAPP-A; } p=0.13 \text { for NT. } \\
\text { c: } p>0.05 \text { when the medians of the MoMs were compared between spontaneous vs IVF (overall) across the mode of conception with Wilcoxon signed-rank } \\
\text { test, Asymptotic significances at a significance level of } 0.05 \text { were } 0.443 \text { for } \beta \text {-hCG, } 0.895 \text { for PAPP-A, and } 0.536 \text { for NT. } \\
\text { MoM: Multiple of median; IVF: In vitro fertilization; ICSI: Intracytoplasmic sperm injection; ET: Embryo transfer; PAPP-A: Pregnancy associated plasma } \\
\text { protein-A; } \beta \text {-hCG: } \beta \text {-human chorionic gonadotropin; NT: Nuchal thickness; ET: Embryo transfer }\end{array}$} \\
\hline
\end{tabular}


Table 3. Summary of the findings of the previous studies evaluating PAPP-A, $\beta$-hCG and NT MoM values in spontaneous and IVF pregnancies

\begin{tabular}{|c|c|c|c|c|c|}
\hline Author & $\mathbf{n}$ & Mode of conception & PAPP-A (MoM) & hCG (MoM) & NT (MoM) \\
\hline Liao et al. (24) & $\begin{array}{l}220 \\
30 \\
1233\end{array}$ & $\begin{array}{l}\text { IVF } \\
\text { ICSI } \\
\text { Control }\end{array}$ & $\begin{array}{l}1.00^{*} \\
0.86^{*} \\
1.09\end{array}$ & $\begin{array}{l}1.21^{* * *} \\
1.09 \\
1.06\end{array}$ & $\begin{array}{l}0.97 \\
1.00 \\
0.98\end{array}$ \\
\hline Niemimaa et al. (31) & $\begin{array}{l}49 \\
4265 \\
\end{array}$ & $\begin{array}{l}\text { IVF } \\
\text { Control }\end{array}$ & $\begin{array}{l}1.03 \\
0.99 \\
\end{array}$ & $\begin{array}{l}1.25^{* *} \\
1.03\end{array}$ & NA \\
\hline Wojdemann et al. (13) & $\begin{array}{l}47 \\
63 \\
3026\end{array}$ & $\begin{array}{l}\text { IVF } \\
\text { OI } \\
\text { Control }\end{array}$ & $\begin{array}{l}1.02 \\
0.89 \\
1.00\end{array}$ & $\begin{array}{l}1.14 \\
1.08 \\
1.00\end{array}$ & $\begin{array}{l}0.97 \\
1.02 \\
1.00\end{array}$ \\
\hline Maymon and Shulman (33) & $\begin{array}{l}71 \\
285\end{array}$ & $\begin{array}{l}\text { IVF } \\
\text { Control }\end{array}$ & $\begin{array}{l}0.96^{*} \\
1.05\end{array}$ & $\begin{array}{l}1.16 \\
1.06\end{array}$ & $\begin{array}{l}1.16 \\
1.06\end{array}$ \\
\hline Orlandi et al. (16) & $\begin{array}{l}74 \\
32 \\
42 \\
370 \\
\end{array}$ & $\begin{array}{l}\text { All ART } \\
\text { IVF } \\
\text { ICSI } \\
\text { Control } \\
\end{array}$ & $\begin{array}{l}0.89 * \\
0.79 * \\
0.96 \\
1.00 \\
\end{array}$ & $\begin{array}{l}0.95 \\
0.84 \\
1.13 \\
1.00\end{array}$ & $\begin{array}{l}1.04 \\
1.10 \\
1.02 \\
1.00\end{array}$ \\
\hline Ghisoni et al. (14) & $\begin{array}{l}50 \\
92 \\
429\end{array}$ & $\begin{array}{l}\text { IVF } \\
\text { ICSI } \\
\text { Control }\end{array}$ & $\begin{array}{l}0.99 \\
0.98 \\
1.02\end{array}$ & $\begin{array}{l}1.16^{*} \\
1.09^{*} \\
0.99\end{array}$ & $\begin{array}{l}1.39^{\mathrm{d}} \\
1.38^{\mathrm{d}} \\
1.50^{\mathrm{d}}\end{array}$ \\
\hline Hui et al. (20) & $\begin{array}{l}92 \\
57 \\
54 \\
31 \\
401 \\
\end{array}$ & $\begin{array}{l}\text { IVF } \\
\text { ICSI } \\
\text { IVF-FET } \\
\text { ICSI-FET } \\
\text { Control } \\
\end{array}$ & $\begin{array}{l}0.83^{*} \\
0.70^{*} \\
0.95 \\
0.66^{*} \\
1.00 \\
\end{array}$ & $\begin{array}{l}0.87^{*} \\
0.82 \\
1.21 \\
0.96 \\
1.00 \\
\end{array}$ & N/A \\
\hline Lambert-Messerlian et al. (15) & $\begin{array}{l}277 \\
323 \\
247 \\
59 \\
56 \\
37070 \\
\end{array}$ & $\begin{array}{l}\text { IVF-OI } \\
\text { IUI-OI } \\
\text { IUI } \\
\text { IVF-OI-ED } \\
\text { IVF-ED } \\
\text { Control } \\
\end{array}$ & $\begin{array}{l}0.94 \\
0.91 * \\
0.98 \\
1.09 \\
1.00\end{array}$ & $\begin{array}{l}1.13 \\
1.06 \\
1.08 \\
0.98 \\
1.22 \\
\end{array}$ & $\begin{array}{l}1.03 \\
1.02 \\
0.97 \\
0.96 \\
0.96\end{array}$ \\
\hline Tul and Novak-Antolic (10) & $\begin{array}{l}130 \\
54 \\
914 \\
\end{array}$ & $\begin{array}{l}\text { IVF } \\
\text { ICSI } \\
\text { Control }\end{array}$ & $\begin{array}{l}0.94^{*} \\
0.82^{*} \\
1.04 \\
\end{array}$ & $\begin{array}{l}1.04 \\
0.91 \\
1.00\end{array}$ & $\begin{array}{l}1.00 \\
0.99 \\
0.99\end{array}$ \\
\hline Anckaert et al. (4) & $\begin{array}{l}163 \\
59 \\
31 \\
4088 \\
\end{array}$ & $\begin{array}{l}\text { ICSI } \\
\text { IVF } \\
\text { FET } \\
\text { Control } \\
\end{array}$ & $\begin{array}{l}0.94^{*} \\
0.75^{*} \\
1.05 \\
1.10 \\
\end{array}$ & $\begin{array}{l}1.07 \\
0.90 \\
1.12 \\
0.97 \\
\end{array}$ & N/A \\
\hline Amor et al. (3) & $\begin{array}{l}1739 \\
50253 \\
\end{array}$ & $\begin{array}{l}\text { IVF } \\
\text { Spontaneous }\end{array}$ & $\begin{array}{l}0.83^{*} \\
1.00 \\
\end{array}$ & $\begin{array}{l}0.99 \\
0.98\end{array}$ & $\begin{array}{l}0.91 * * \\
0.90\end{array}$ \\
\hline Gjerris at al. (7) & $\begin{array}{l}992 \\
512 \\
396 \\
84 \\
2532 \\
\end{array}$ & $\begin{array}{l}\text { All ART } \\
\text { IVF } \\
\text { ICSI } \\
\text { FET } \\
\text { Control } \\
\end{array}$ & $\begin{array}{l}0.80 * \\
0.78 * \\
0.79 * \\
1.03 \\
0.98 \\
\end{array}$ & $\begin{array}{l}0.97 \\
0.96 \\
0.98 \\
1.00 \\
0.99 \\
\end{array}$ & $\begin{array}{l}0.92^{*} \\
0.90 \\
0.95 \\
0.94 \\
1.00 \\
\end{array}$ \\
\hline Engels et al. (6) & $\begin{array}{l}203 \\
592 \\
192 \\
572 \\
\end{array}$ & $\begin{array}{l}\text { IVF } \\
\text { Control } \\
\text { ICSI } \\
\text { Control } \\
\end{array}$ & $\begin{array}{l}0.756^{*} \\
1.029 \\
0.708^{*} \\
1.061 \\
\end{array}$ & $\begin{array}{l}0.937 \\
1.086 \\
1.041 \\
1.090\end{array}$ & $\begin{array}{l}0.939 \\
1.013 \\
0.976 \\
0.987\end{array}$ \\
\hline Bender et al. (5) & $\begin{array}{l}110 \\
331 \\
1431\end{array}$ & $\begin{array}{l}\text { IVF } \\
\text { ICSI } \\
\text { Control }\end{array}$ & $\begin{array}{l}0.86^{*} \\
0.9^{*} \\
1.06\end{array}$ & $\begin{array}{l}1.10 \\
1.10 \\
0.94\end{array}$ & $\begin{array}{l}1.03 \\
1.02 \\
1.00\end{array}$ \\
\hline
\end{tabular}


Table 3. Continued

\begin{tabular}{|l|l|l|l|l|l|}
\hline Author & n & Mode of conception & PAPP-A (MoM) & hCG (MoM) & NT (MoM) \\
\hline & 282 & All ART & $0.83^{\mathrm{a}}$ & 0.98 & 1.00 \\
Matilainen et al. (9) & 176 & IVF-ICSI & $0.82^{\mathrm{b}}$ & 1.00 & 1.03 \\
& 87 & FET & 0.78 & 0.94 & 1.00 \\
& 19 & HRT-FET & 0.66 & 0.83 & 0.96 \\
& 24783 & Control & 0.94 & 1.02 & 0.97 \\
\hline
\end{tabular}

The number of cases and mode of conception sand their test results are shown. *Significantly lower compared with the control group, **Significantly higher compared with the control group, ${ }^{\mathrm{a}} \mathrm{p} \leq 0.03$, all ART vs control ${ }^{\mathrm{b}} \mathrm{p} \leq 0.01$, IVF/ICSI vs control. NA: Not applicable, IVF: In vitro fertilization, ICSI: Intracytoplasmic sperm injection, ART: Assisted reproduction technologies, FET: Frozen embryo transfer, IUI: Intrauterine insemination, OI: Ovulation induction, ED: Egg donation, ${ }^{\mathrm{m}}$ Expressed as mean, ${ }^{\mathrm{d}}$ Expressed as mean in millimeter

patients. However, when age-matched controls were used and age-adjusted analysis was perfomed, the false-positive rate remained persistently high in these IVF pregnancies $(3,24)$. Of particular note, clinically recognized twin pregnancies can be spontaneously reduced to singleton in IVF/ICSI twin pregnancies known as vanishing twin phenomenon. These pregnancies are characterized by higher maternal MoM values of PAPP-A and $\beta$-hCG $(25,26)$. Therefore, the results should be carefully analyzed when there is another gestational sac empty or filled with a dead fetus. PAPP-A is a protease of insulin-like growth factor (IGF) binding protein- 4 produced by decidua and trophoblastic tissue, and plays critical roles during human implantation such as the regulation of IGF bioavailability in the placental bed $(27,28)$. Therefore, taken together, these findings suggest that IVF pregnancies are likely to be different from spontaneous pregnancies and that IVF treatment itself can modify the implantation process leading to lower PAPP-A levels, which are not always associated with clinically recognized abnormal pregnancy outcomes.

PAPP-A circulates at very low levels in non-pregnant women. Like $\beta$-hCG, it is produced at high levels by the placenta during pregnancy (29). We could not find any differences in the temporal relation of $\beta$-hCG and PAPP-A with each other and gestational age between natural and IVF conceptions. This situation provides supporting evidence for the notion that IVF pregnancies are not different from spontaneous pregnancies in terms of the first trimester biomarkers.

The other biochemical marker in the first trimester screening test is $\beta$-hCG. High levels of $\beta$-hCG in the first trimester are associated with increased risk of Down syndrome, whereas its elevated levels in the second trimester are more related to poor obstetric outcomes (30). Although some studies reported increased $(5,11,14,15,31)$ or decreased $\beta$-hCG MoM levels in ART pregnancies compared with controls (6), a great majority of the studies including ours found no difference in the levels of $\beta$-hCG levels between natural and ART pregnancies $(3,4,6,7,9,10,16,20,32)$. These inconsistent findings have been attributed to small sample sizes, the heterogeneity of study populations, and the differences of $\beta$-hCG levels at different gestational weeks $(3,18,32)$.
Another important finding of our study is that IVF pregnancies after fresh ET cycles had similar first trimester screening profiles to those of frozen ET cycles. This information could be relevant because a limited number of studies have thus far analyzed the first trimester screening profiles of ART pregnancies conceived after fresh and frozen ET cycles and reported varying results $(3,4,7,9,20)$. Some of these studies reported significantly reduced median PAPP-A MOM values for pregnancies after fresh IVF and ICSI cycles, whereas median PAPP-A MOM values of pregnancies after frozen cycles were similar to those of spontaneous pregnancies $(4,7)$. Hui et al. (20) studied both IVF and ICSI cycles with fresh and frozen-thawed ET. PAPP-A was significantly decreased in fresh IVF, fresh ICSI, and frozen ICSI pregnancies but not in frozen IVF pregnancies. Fresh and frozen ICSI groups had comparable median PAPP-A MoMs (20). In another study, Matilainen et al. (9) compared spontaneous pregnancies, fresh IVF/ICSI cycles, and frozen-thawed ET with and without hormone stimulation. The median PAPP-A MoM value for fresh cycles was significantly lower than in the control group. Frozen transfer groups, with and without hormone treatment, had lower MoM values than the control group. Interestingly, fresh and frozen-thawed transfer cycles in which exogenous hormones (follicle-stimulating agents, or any combination of estrogen and progesterone) were used had significantly lower PAPP-A values when compared with fresh and frozen-thawed cycles without hormones as shown by Amor et al. (3) who compared 773 fresh cycles with 573 frozen-thawed cycles. A recent meta-analysis documented that free $\beta$-hCG tests showed slightly higher values in the ICSI group than controls (RR=1.09, 95\% CI: 1.03-1.16) but not in the IVF group (RR=1.03, 95\% CI: 0.94-1.12). Pregnancyassociated plasma protein-A values for IVF/ICSI, IVF, and ICSI showed lower values in comparison with controls (RR, 95\% CI: $0.85,0.80-0.90 ; 0.82,0.74-0.89$ and $0.83,0.79-0.86$, respectively). The nuchal translucency measurement showed no statistical differences between study groups (IVF and ICSI) and controls $(\mathrm{RR}=1.00,95 \% \mathrm{CI}: 0.94-1.08$ and $\mathrm{RR}=1.01,95 \% \mathrm{CI}: 0.97-1.05$, respectively) (12).

NT is the only ultrasound marker in the first trimester combined screening test. Most studies have shown similar mean MoM 
values for NT in natural and IVF pregnancies $(3,5,6,9,10,13,16,24)$. A few studies found thicker (33) and thinner NT values $(7,32)$ for the general IVF population. However, all studies on fresh and frozen-thawed ET cycles reported comparable NT MoM values for both. In support of this, our results revealed no significant variations in the MoMs of NT between spontaneous and IVF pregnancies.

Our results show that the results of the first trimester combined test did not differ between natural and IVF pregnancies when a homogenous patient population comparable for maternal age, gestation, BMI, ethnicity, and ovarian stimulation protocol was analyzed. On the other hand, test results should be interpreted cautiously in IVF pregnancies because many studies reported that the biochemical markers of the test might be affected by several factors in these pregnancies such as the mode of conception, etiology of infertility, maternal age, ovarian stimulation, and vanishing twins.

Ethics Committee Approval: IRB approval no: IRB\# 2015.207. IRB2.077.

Informed Consent: Informed consent was obtained in all patient.

Peer-review: Externally peer-reviewed.

Author Contributions: Concept - O.O.; Design - O.O.; Data Collection - E.G., Y.G., O.O., H.Y., Z.S.; Processing - E.G., Y.G., O.O., H.Y., Z.S.; Analysis and/or Interpretation - E.G., Y.G., O.O., H.Y., Z.S., B.B., B.U.; Writer - Y.G., O.O.

Conflict of Interest: No conflict of interest is declared by the authors.

Financial Disclosure: The authors declared that this study received no financial support.

\section{References}

1. Nicolaides KH. Nuchal translucency and other first-trimester sonographic markers of chromosomal abnormalities. Am J Obstet Gynecol 2004; 191: 45-67.

2. Nicolaides KH. Screening for fetal aneuploidies at 11 to 13 weeks. Prenat Diagn 2011; 31: 7-15.

3. Amor DJ, Xu JX, Halliday JL, Francis I, Healy DL, Breheny S, et al. Pregnancies conceived using assisted reproductive technologies (ART) have low levels of pregnancy-associated plasma protein-A (PAPP-A) leading to a high rate of false-positive results in first trimester screening for Down syndrome. Hum Reprod 2009; 24: 1330-8.

4. Anckaert E, Schiettecatte J, Sleurs E, Devroey P, and Smitz J. First trimester screening for Down's syndrome after assisted reproductive technology: non-male factor infertility is associated with elevated free beta-human chorionic gonadotropin levels at 10-14 weeks of gestation. Fertil Steril 2008; 90: 1206-10.
5. Bender F, Hecken J, Reinsberg J, Berg C, van der Ven H, Gembruch $\mathrm{U}$, et al. Altered first-trimester screening markers after IVF/ICSI: no relationship with small-for-gestational-age and number of embryos transferred. Reprod Biomed Online 2010; 20: 516-22.

6. Engels MA, Kooij M, Schats R, Twisk JW, Blankenstein MA, van Vugt JM. First-trimester serum marker distribution in singleton pregnancies conceived with assisted reproduction. Prenat Diagn 2010; 30: 372-7.

7. Gjerris AC, Loft A, Pinborg A, Christiansen M, Tabor A. First-trimester screening markers are altered in pregnancies conceived after IVF/ ICSI. Ultrasound Obstet Gynecol 2009; 33: 8-17.

8. Kagan KO, Wright D, Spencer K, Molina FS, Nicolaides KH. Firsttrimester screening for trisomy 21 by free beta-human chorionic gonadotropin and pregnancy-associated plasma protein-A: impact of maternal and pregnancy characteristics. Ultrasound Obstet Gynecol 2008; 31: 493-502

9. Matilainen M, Peuhkurinen S, Laitinen P, Jarvela I, Morin-Papunen L, Ryynanen M. In combined first-trimester Down syndrome screening, the false-positive rate is not higher in pregnancies conceived after assisted reproduction compared with spontaneous pregnancies. Fertil Steril 2011; 95: 378-81.

10. Tul N, Novak-Antolic Z. Serum PAPP-A levels at 10-14 weeks of gestation are altered in women after assisted conception. Prenat Diagn 2006; 26: 1206-11.

11. Bersinger NA, Wunder D, Vanderlick F, Chanson A, Pescia G, Janecek P, et al. Maternal serum levels of placental proteins after in vitro fertilisation and their implications for prenatal screening. Prenat Diagn 2004; 24: 471-7.

12. Cavoretto P, Giorgione V, Cipriani S, Vigano P, Candiani M, Inversetti A, et al. Nuchal translucency measurement, free beta-hCG and PAPP-A concentrations in IVF/ICSI pregnancies: systematic review and meta-analysis. Prenat Diagn 2017; 37: 540-55.

13. Wojdemann KR, Larsen SO, Shalmi A, Sundberg K, Christiansen M, Tabor A. First trimester screening for Down syndrome and assisted reproduction: no basis for concern. Prenat Diagn 2001; 21: 563-5.

14. Ghisoni L, Ferrazzi E, Castagna C, Levi Setti PE, Masini AC, Pigni A. Prenatal diagnosis after ART success: the role of early combined screening tests in counselling pregnant patients. Placenta 2003; 24(Suppl B): 99-103.

15. Lambert-Messerlian G, Dugoff L, Vidaver J, Canick JA, Malone FD, Ball RH, et al. First- and second-trimester Down syndrome screening markers in pregnancies achieved through assisted reproductive technologies (ART): a FASTER trial study. Prenat Diagn 2006; 26: $672-8$

16. Orlandi F, Rossi C, Allegra A, Krantz D, Hallahan T, Orlandi E, et al First trimester screening with free beta-hCG, PAPP-A and nuchal translucency in pregnancies conceived with assisted reproduction. Prenat Diagn 2002; 22: 718-21.

17. Nicolaides K. The 11-13+6 Weeks Scan. London: Fetal Medicine Foundation, 2004

18. Gjerris AC, Tabor A, Loft A, Christiansen M, Pinborg A. First trimester prenatal screening among women pregnant after IVF/ICSI. Hum Reprod Update 2012; 18: 350-9.

19. Frendo JL, Vidaud M, Guibourdenche J, Luton D, Muller F, Bellet $\mathrm{D}$, et al. Defect of villous cytotrophoblast differentiation into syncytiotrophoblast in Down's syndrome. J Clin Endocrinol Metab 2000; 85: 3700-7.

20. Hui PW, Lam YH, Tang MH, Ng EH, Yeung WS, Ho PC. Materna serum pregnancy-associated plasma protein-A and free betahuman chorionic gonadotrophin in pregnancies conceived with fresh and frozen-thawed embryos from in vitro fertilization and intracytoplasmic sperm injection. Prenat Diagn 2005; 25: 390-3. 
21. Pihl K, Larsen T, Krebs L, Christiansen M. First trimester maternal serum PAPP-A, beta-hCG and ADAM12 in prediction of small-forgestational-age fetuses. Prenat Diagn 2008; 28: 1131-5.

22. Rifouna MS, Reus AD, Koning AH, van der Spek PJ, Exalto N, Steegers EA, et al. First trimester trophoblast and placental bed vascular volume measurements in IVF or IVF/ICSI pregnancies. Hum Reprod 2014; 29: 2644-9.

23. Ranta JK, Raatikainen K, Romppanen J, Pulkki K, Heinonen S. Increased time-to-pregnancy and first trimester Down's syndrome screening. Hum Reprod 2010; 25: 412-7.

24. Liao AW, Heath V, Kametas N, Spencer K, Nicolaides KH. Firsttrimester screening for trisomy 21 in singleton pregnancies achieved by assisted reproduction. Hum Reprod 2001; 16: 15014.

25. Chasen ST, Perni SC, Predanic M, Kalish RB, Chervenak FA. Does a "vanishing twin" affect first-trimester biochemistry in Down syndrome risk assessment? Am J Obstet Gynecol 2006; 195: 236-9.

26. Pinborg A, Lidegaard O, Freiesleben NI, Andersen AN. Vanishing twins: a predictor of small-for-gestational age in IVF singletons. Hum Reprod 2007; 22: 2707-14.

27. Qiu Q, Bell M, Lu X, Yan X, Rodger M, Walker M, et al. Significance of IGFBP-4 in the development of fetal growth restriction. J Clin Endocrinol Metab 2012; 97: 1429-39.
28. Giudice LC, Conover CA, Bale L, Faessen GH, Ilg K, Sun I, et al. Identification and regulation of the IGFBP-4 protease and its physiological inhibitor in human trophoblasts and endometrial stroma: evidence for paracrine regulation of IGF-II bioavailability in the placental bed during human implantation. J Clin Endocrinol Metab 2002; 87: 2359-66.

29. Leguy MC, Brun S, Pidoux G, Salhi H, Choiset A, Menet MC, et al. Pattern of secretion of pregnancy-associated plasma protein-A (PAPP-A) during pregnancies complicated by fetal aneuploidy, in vivo and in vitro. Reprod Biol Endocrinol 2014; 12: 129.

30. Spencer K. Second-trimester prenatal screening for Down syndrome and the relationship of maternal serum biochemical markers to pregnancy complications with adverse outcome. Prenat Diagn 2000; 20: 652-6.

31. Niemimaa M, Heinonen S, Seppala M, Hippelainen M, Martikainen $\mathrm{H}$, Ryynanen M. First-trimester screening for Down's syndrome in in vitro fertilization pregnancies. Fertil Steril 2001; 76: 1282-3.

32. Engels MA, Pajkrt E, Groot DT, Schats R, Twisk JW, van Vugt JM. Validation of correction factors for serum markers for first-trimester Down syndrome screening in singleton pregnancies conceived with assisted reproduction. Fetal Diagn Ther 2013; 34: 217-24.

33. Maymon R, Shulman A. Integrated first- and second-trimester Down syndrome screening test among unaffected IVF pregnancies. Prenat Diagn 2004; 24: 125-9. 